\title{
Petrography and origin of the Lower Ordovician microbial carbonates in the Songzi Area of Hubei Province, middle Yangtze region, China
}

\author{
Chuan-Tao Xiao ${ }^{1} \cdot$ Guo-Qi Wei $^{2} \cdot$ Zhen-Yu Song $^{1} \cdot$ Yun-Peng Xiao ${ }^{1} \cdot$ Wei Yang $^{2} \cdot$ Man Dong $^{1} \cdot$ Yun-Fei Huang ${ }^{1} \cdot$ Da Gao $^{1}$
}

Received: 15 May 2018 / Published online: 16 August 2019

(c) The Author(s) 2019

\begin{abstract}
This study is the first systematic assessment of the Lower Ordovician microbial carbonates in Songzi, Hubei Province, China. This paper divides the microbial carbonates into two types according to growth patterns, namely nongranular and granular. The nongranular types include stromatolites, thrombolites, dendrolites, leiolites and laminites; the granular types are mainly oncolites and may include a small amount of microbiogenic oolite. According to their geometric features, the stromatolites can be divided into four types: stratiform, wavy, columnar and domal. Additionally, dipyramidal columnar stromatolites are identified for the first time and represent a new type of columnar stromatolite. The thrombolites are divided into three types: speckled, reticulated and banded. The grazing gastropod Ecculiomphalus and traces of bioturbation are observed in the speckled and reticulated thrombolites. This paper considers these two kinds of thrombolites to represent bioturbated thrombolites. These findings not only fill gaps in the field of domestic Ordovician bioturbated thrombolites but also provide new information for the study of thrombolites. Based on the analysis of the sedimentary characteristics of microbialites, the depositional environments of the various types of microbialites are described, and the distribution patterns of their depositional environments are summarized. The relationship between the development of microbialites and the evolution and radiation of metazoans during the Early to Middle Ordovician is discussed. Consistent with the correspondence between the stepwise and rapid radiation of metazoans and the abrupt reduction in the number of microbialites between the late Early Ordovician and the early Middle Ordovician, fossils of benthonic grazing gastropods (Ecculiomphalus) were found in the stromatolites and thrombolite of the study area. It is believed that the gradual reduction in microbialites was related to the rapid increase in the abundance of metazoans. Grazers not only grazed on the microorganisms that formed stromatolites, resulting in a continuous reduction in the number of stromatolites, but also disrupted the growth state of the stromatolites, resulting in the formation of unique bioturbated thrombolites in the study area. Hydrocarbon potential analysis shows that the microbialites in the Nanjinguan Formation represent better source rocks than those in the other formations.
\end{abstract}

Keywords Microbial carbonate $\cdot$ Stromatolites $\cdot$ Thrombolites $\cdot$ Oncolite $\cdot$ Lower Ordovician $\cdot$ Songzi Area

\section{Introduction}

Microbial carbonate is the main component of microbialites. In the past 20 years, microbialites have been seen to define a depositional construction of carbonate formed by benthic microflora. The term microbialite refers to the precipitation of carbonates caused by benthic microflora through biochemical processes and the trapping and binding of detrital particles (Burne and Moore 1987). This type of deposition has occurred since the Proterozoic and forms reefs and carbonate sediments, including stromatolites, thrombolites, dendrites and oncolites. Many case studies are available in the literature (Golubic 1973, 1976; Zhang and Hofmann 1982; Hofmann 1987; Zhuravlev and Wood 1996; Feldmann 
and McKenzie 1997; Knoll and Semikhatov 1998; Myrow 2002; Riding 1991, 2000; Riding and Liang 2005; Rowland and Shapiro 2002; Kruse and Zhuravlev 2008; Hicks and Rowland 2009; Adachi et al. 2011). The Lower Ordovician marine carbonate deposits in the Yangtze Plate developed continuously, and the associated microbialites and reefs are widely distributed (Zhu et al. 1990, 1995, 2006; Mei and Lu 1991; Li and Wu 2001; Yang 2018; Xiao et al. 1993, 1995, 2004, 2011; Adachi et al. 2011; Wang et al. 2012). During the Early Ordovician, the middle Yangtze platform was occupied by different types of microorganisms and metazoans at different times. Microorganisms can form reefs alone or in conjunction with metazoans. The formation of microbialites is linked to events such as environmental, climatic and sea-level changes. Researchers in China and elsewhere have undertaken considerable work on the Lower Ordovician microbialites and reefs, especially the latter (Zhu et al. 1990, 1995, 2006; Mei and Lu 1991; Li and Wu 2001; Yang 2018; Xiao et al. 1993, 1995, 2004, 2011; Adachi et al. 2011; Wang et al. 2012). However, the research has mainly focused on macroscopic feature description of stromatolites, and systematic research on stromatolites and other Ordovician microbialites is very rare. There is no systematic classification or detailed study on the microbialites in Lower Ordovician strata, and the successional relationships of microbialites in the strata have not been determined (Zhu et al. 1990, 1995, 2006; Mei and Lu 1991; Li and Wu 2001; Yang 2018; Xiao et al. 1993, 1995, 2004, 2011; Adachi et al. 2011; Wang et al. 2012). Furthermore, there are few studies on the relationship between the evolution of microbialites and the evolution of metazoans. In view of these shortcomings, the authors believe that a systematic study of Ordovician microbialites will not only enrich the understanding of the stratigraphy by better characterizing the microbialites and types of microbialites in China but is also of economic significance for the exploration of Ordovician source rocks.
Even more importantly, the results of this study are of great scientific value for exploring the relationship between microbialite development and the radiation of metazoans in the Middle Ordovician.

\section{Regional geological background}

The microbialites discovered in the study area formed in the Early Ordovician in the Liujiachang area in southern Songzi, Hubei Province (Fig. 1). Geotectonically, this area is located on the southern edge of the middle Yangtze platform and the Jianghan basin. The Ordovician stratigraphy is complete in the study area, and the stratigraphic sequence is consistent with that in the Three Gorges area. The Lower Ordovician strata in the study area include the Nanjinguan Formation, the Fenxiang Formation and the Honghuayuan Formation from bottom to top. The Middle Ordovician strata include the Dawan Formation and the Guniutan Formation. The Upper Ordovician strata include the Datianba Formation, the Baota Formation, the Linxiang Formation and the Wufeng Formation, but the Wufeng Formation is absent in the study area. The Ordovician strata in the study area are dominated by carbonate rocks that are sandwiched between shale and calcareous shale, and the total thickness of the strata in the study area is approximately $463 \mathrm{~m}$. In terms of regional structure, the Ordovician strata of the study area are distributed on the peripheries of the Renheping syncline, which contains a core of Triassic strata, and the Liujiachang anticline, which contains a core of Cambrian strata. During the Ordovician period, the study area experienced a range of sedimentary environments, including restricted platform facies, open platform facies, submerged platform facies, broad continental shelf facies and deep-water facies in the Late Ordovician (Xiao et al. 1996, 2016; Xu et al. 2004). In some of these environments, stromatolites developed in
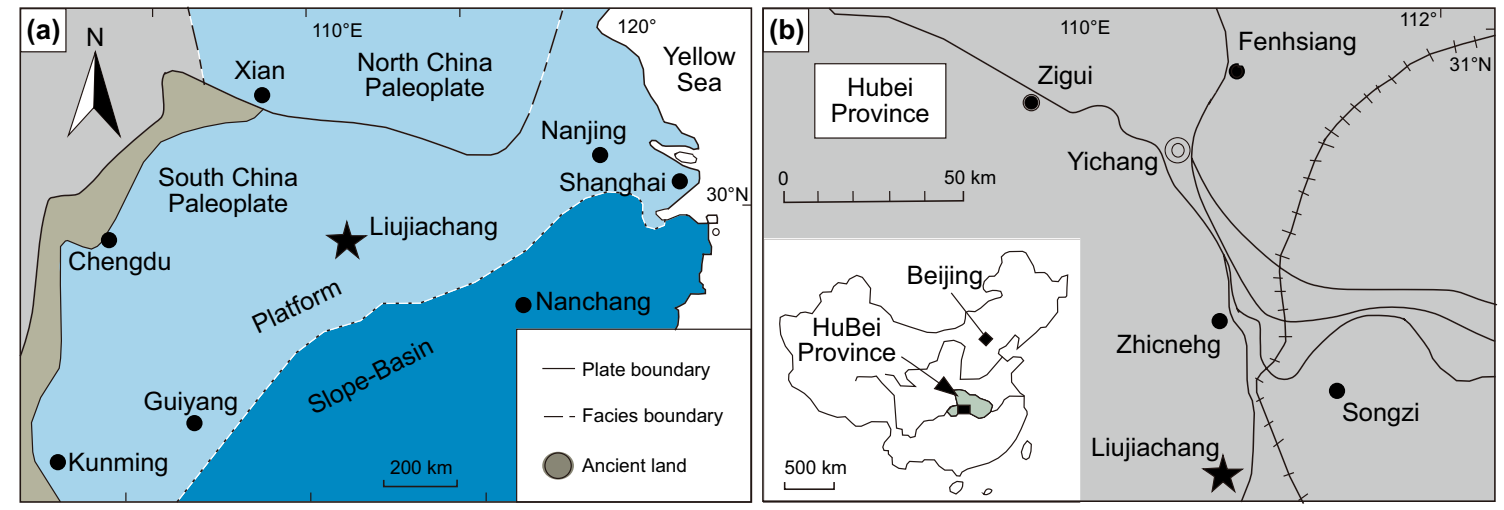

Fig. 1 Location of Songzi Area, South China. a Early Ordovician paleogeographic reconstruction; the star shows the location of the Liujiachang section and Huanghuachang section. Paleogeographic map modified from Natsuko Adachi et al. (2011). b Index map of Liujiachang section and Huanghuachang section 
the Nanjinguan, the Fenxiang and the Honghuayuan Formations, and these stromatolites form the most distinctive microbialite deposits in the Lower Ordovician strata in the study area.

The stromatolites documented in this study are mainly found in the Nanjinguan, Fenxiang and Honghuayuan Formations in the study area (Fig. 2). The lower parts of the Nanjinguan Formation are thick gray layers of blocky sparry calcarenite, sparry calcirudite, thrombolite limestone, stromatolitic limestone and banded muddy limestone intercalated with yellow-gray shale, with a thickness of $76.5 \mathrm{~m}$. The upper part of the Nanjinguan Formation consists of gray to medium-grained sparry calcarenite, gray thick to massive sparry calcirudite and dolomitic limestone containing thrombolites, with a thickness of approximately $97.8 \mathrm{~m}$. Many fossils appear in the Nanjinguan Formation. According to the occurrences of the fossils, they can be clearly divided into two assemblages: the Dactylocephalus dactyloides-Asaphopsis granulatus assemblage in the lower part of the Nanjinguan Formation, and the Szechuanella szechuanensis-Pseudobasilicus sp. assemblage in the upper part. The lower assemblage is a component of the lower $D$. dactyloides - A. inflatus zone of the Nanjinguan Formation in the Yichang section, and the upper assemblage is also an important component in the lower part of the Nanjinguan Formation in the Yangtze region of China. Huaqiao of Changyang and Xiejiaping of Songzi belong to the upper layer of $D$. dactyloides. Asaphopsis is an important fossil in the lower part of the Tremadocian stage in Western Europe and North America. Therefore, the Nanjinguan Formation in the study area can be compared with the same formation in the Yichang area and belongs to the era of the early Tremadocian (Zhu et al. 1995; Xiao et al. 1996; Xu et al. 2004).

The lower part of the Fenxiang Formation is mainly composed of gray medium-bedded sparry calcarenite, oncolitic limestone and calcirudite with shale. The upper stratum is composed of interbedded rocks containing muddy bioclastic limestone, biosparite limestone, thickbedded stromatolitic limestone, etc. There are abundant fossils in the Fenxiang Formation, and the thickness of this formation is $71 \mathrm{~m}$. The trilobite Tungtzeella szechuanensis, T. sp., which is widely distributed, are characteristic fossils of the Fenxiang Formation and its considerable strata in the Yangtze area. The important graptolite fossils in the study area are Acanthograptus sinensis and A. sinensis var. fenhsiangensis. Acanthograptus is widely distributed in the upper part of the Tonglu Formation in Yunnan, Guizhou and Sichuan Provinces. It is a representative fossil of the Fenxiang Formation. Drepanodus arcuatus, Paltodus deltifer and Paroistodus numarcuatus are important conodonts, and Paltodus deltifer is an important fossil that first appears at the bottom of the Fenxiang Formation and disappears at the top of the Fenxiang Formation. Drepanodus arcuatus is an important component of the $P$. deltifer-Triangulodus proteus zone in the Fenxiang Formation. Paroistodus numarcuatus is an important fossil in the upper Tremadocian stage in Europe. Therefore, the Fenxiang Formation should belong to the late Tremadocian period (Zhu et al. 1995; Xiao et al. 1996, 2016; Xu et al. 2004).

The Honghuayuan Formation is characterized by the development of moderately thick-bedded sparry calcarenite and biogenic reef limestone, with 2-3 beds of yellow-brown shale. The thickness of the formation is approximately 40-55 m. Among the limestones in the Honghuayuan Formation, reefs consisting of Calathium, sponges, blue-green algae, etc., are generally well developed and rich in fossils. The many fossils include Coreanoceras cf. reniformis, Manchuroceras yangtzeense and M. hubeiense, which are characteristic of the Honghuayuan Formation in the Yichang area. These fossils can be compared with the fossils of the Liangjiashan Formation in North China, the Shorin Formation in North Korea, the Upper Canadian Formation in North America, the Tasmanian Stage in Oceania and a Lower Ordovician formation in Siberia. All of these fossils belonged to the early Arenigian period (Zhu et al. 1995; Xiao et al. 1996, 2016; Xu et al. 2004).

\section{Microbialite types and characteristics}

There are different division schemes for the types of microbialites. Riding divided microbialites into four categories based on their macroscopic components, namely stromatolites, thrombolites, dendrolites and leiolites (Riding 2000), which are basically consistent with Shapiro's classification of medium structures (Shapiro and Awramik 2006). Mei Mingxiang, a scholar in China, supplemented the classification system of microbialites. He used laminite and oncolite as two types of microbialites (Mei 2007a). Based on the growth form of microbialites, microbialites are divided into two major types in this paper, namely nongranular and granular types. The nongranular type microbialites mainly include stromatolites, thrombolites, dendrolites, leiolites and laminites. The granular types of microbialites are mainly oncolites and may include a small amount of microbiogenic oolite.

\subsection{Nongranular types of microbialite}

The nongranular microbialites grow in forms that are laminated or nonlaminated. These types formed through the process of the microbial community capturing and 


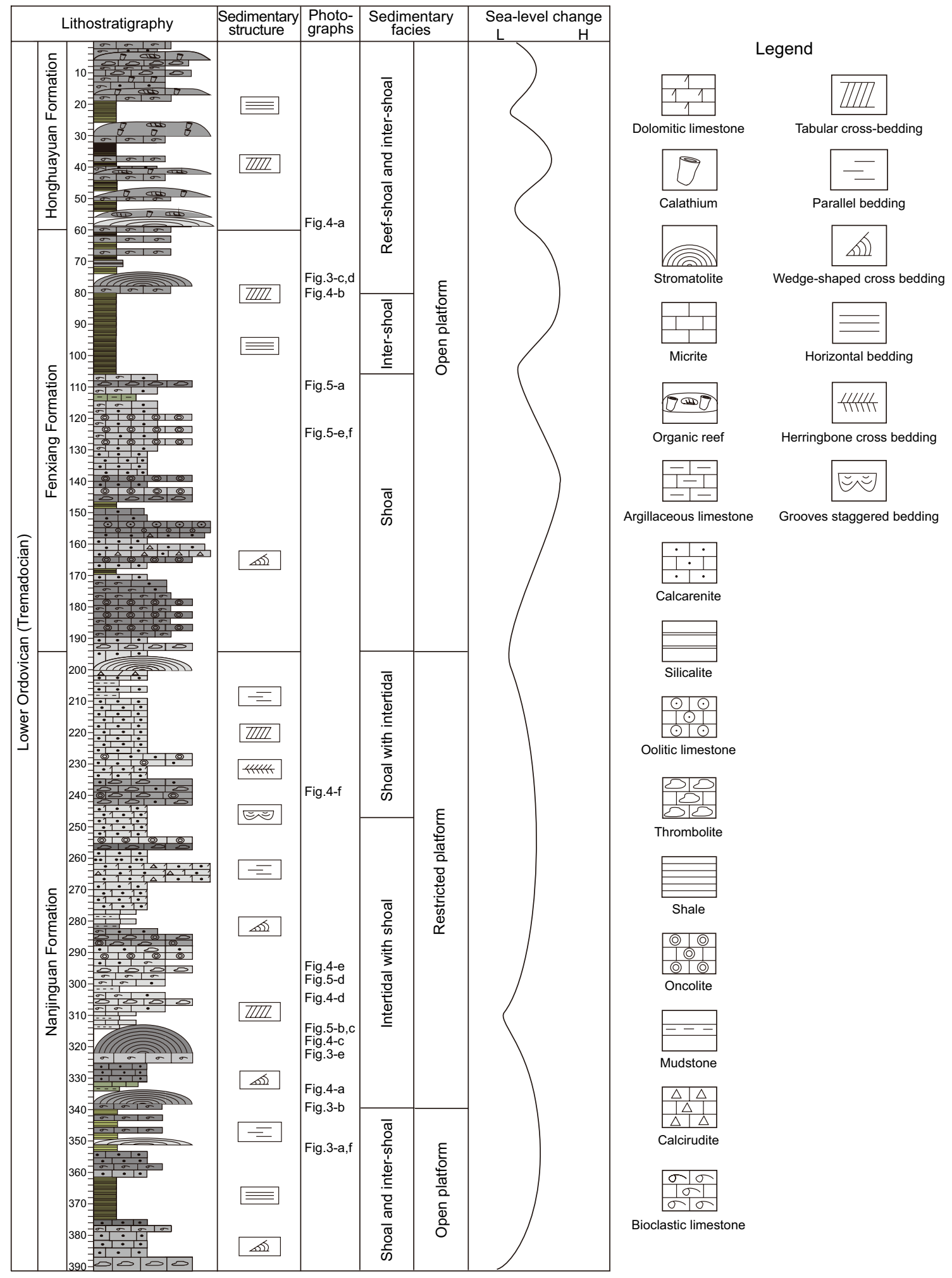

Fig. 2 Lithofacies column of the Lower Ordovician in the Songzi Area

binding detrital particles or causing carbonate to precipitate because of biochemical processes. These processes can form a laminated or nonlaminated carbonate deposit. This kind of microbialite includes stromatolites, thrombolites, dendrolites and leiolites; the research area is dominated by the first two. 


\subsubsection{Stromatolites}

The classification scheme for stromatolites is relatively complex. There are currently four major classification methods. The first classification scheme is based on the genesis of stromatolites. Stromatolites can be classified as skeletal stromatolites, bonded stromatolites, travertine stromatolites, fine granulated stromatolites and land stromatolites (Riding 2000). The second scheme involves classifying stromatolites according to their morphology and classifying them into superformations, e.g., formations, shapes and subtypes (Zhu 1993). Third, the genus and species of stromatolites can be classified according to the double name method used in biology (Cloud and Semikhatov 1969; Semikhatov and Raaben 2000), but the genus and species names are not related to biological evolution. The fourth scheme is based on stromatolite geometry classification, which includes the divisions of stratiform stromatolite, wavy stromatolite, domal stromatolite, columnar stromatolite and finger stromatolite (Aitken 1967). Some scholars have discussed the classification of stromatolites (Cao et al. 2009; Cao and Yuan 2006). This article does not repeat such works. As previous studies on Ordovician stromatolites are rare, this paper classifies the stromatolites in the study area into the following types based on their geometric features: stratiform stromatolite, wavy stromatolite, columnar stromatolites and domal stromatolite. Among them, the dipyramidal columnar stromatolite is a newly discovered subclass of columnar stromatolite.

\section{(1) Stratiform stromatolites}

Stratiform stromatolites, also known as sheet stromatolites, are characterized by near-horizontal (Fig. 3a) or slightly undulatory laminae. Stratiform stromatolites are relatively well developed in the study area and are found in the Nanjinguan and Fenxiang Formations. The appearance of the laminated limestone is thick to massively bedded, and the strata are nearly horizontal, with slightly wavy local undulations. In field outcrop, the laminae of this stromatolite are rough, and a small amount of biological debris and sand debris can be seen locally between the laminae. In the Nanjinguan Formation, small irregular agglutinated organic matters were observed locally along dark layers of laminar stromatolites, and the clot sizes varied from 1 to $2 \mathrm{~mm}$. These deposits feature clear alternations between light and dark layers; the dark laminae are dark gray irregular continuous layers, whereas the light laminae are gray irregular intermittent layers. The light layers are thicker than the dark layers on the whole. The thickness of the light and dark laminae together is approximately $7-15 \mathrm{~mm}$, and the thickness of the dark laminae is 1-5 mm. The single-layer thickness of stratiform stromatolite limestone in the study area is not consistent and ranges from approximately $0.4-3.6 \mathrm{~m}$, but the single-layer thickness is slightly greater in the Nanjinguan Formation than in the Fenxiang Formation.

In terms of the characteristics of microfacies, the stratiform stromatolites contain a heterogeneous structure. In general, the internal composition of stromatolites is dominated by microcrystalline calcite, followed by a small amount of biological debris, such as echinoderm, brachiopod and trilobite fragments, and locally very small amounts of arenaceous sediment. In some stromatolites, the dark laminae can become a dark microclot in the lateral direction, and the clots are also composed of micritic clusters. A large number of microorganisms, such as Girvanella (Fig. 3f), are visible as filamentous, fine tubular components that are parallel or intertwined in the dark stromatolite layer. These structures are distributed approximately parallel to laminae and are mostly surrounded by micritic to microcrystalline calcite. Dolomite crystals can also be found in the stromatolites.

\section{(2) Wavy stromatolites}

Wavy stromatolites are the most widely developed type of microbialite in the study area and are distributed in the Nanjinguan, Fenxiang Formation and Honghuayuan Formations (Fig. 3b, c). The laminae in this type of structure possess undulating features in the medium structure. In terms of macroscopic characteristics, the beds containing the wavy laminae in the Nanjinguan and Fenxiang Formations are thick bedded to massive bedded and are laterally distributed between the laminated and columnar stromatolite types. The undulation pattern of wavy stromatolites is regular; the wavelength varies from $5 \mathrm{~cm}$ to $40 \mathrm{~cm}$ with an average of approximately $15 \mathrm{~cm}$, and the wave height ranges from 1 to $15 \mathrm{~cm}$, with an average of approximately $5 \mathrm{~cm}$. The appearance of the stromatolites in the Honghuayuan Formation is mostly massive or domal, and their laminae are irregularly wavy, with a wavelength of approximately $6-10 \mathrm{~cm}$ and a wave height of $5-15 \mathrm{~cm}$. In outcrop in the field, the laminae are rough, uneven in thickness, and vary in thickness. From the lateral distribution perspective, some dark laminae in the wavy stromatolites of the Nanjinguan Formation turn into tiny clots laterally, with a clot size of 1-2 mm.

In terms of microfacies, the internal structure of the wavy stromatolites is also not uniform. The material between the laminae is mainly micritic calcite, followed by a small amount of bioclastic and arenaceous sediment. The bioclasts are mainly echinoderm fragments, followed by brachiopod and other marine organism fragments. The local dark-colored laminae change laterally into small clots (clots means small irregular agglutinated organic matter) that consist of micritic clusters. The valleys between adjacent wavy laminae are filled with many bioclasts and arenaceous sediment, which constitute important microfacies in the wavy stromatolite, i.e., interchannel microfacies 

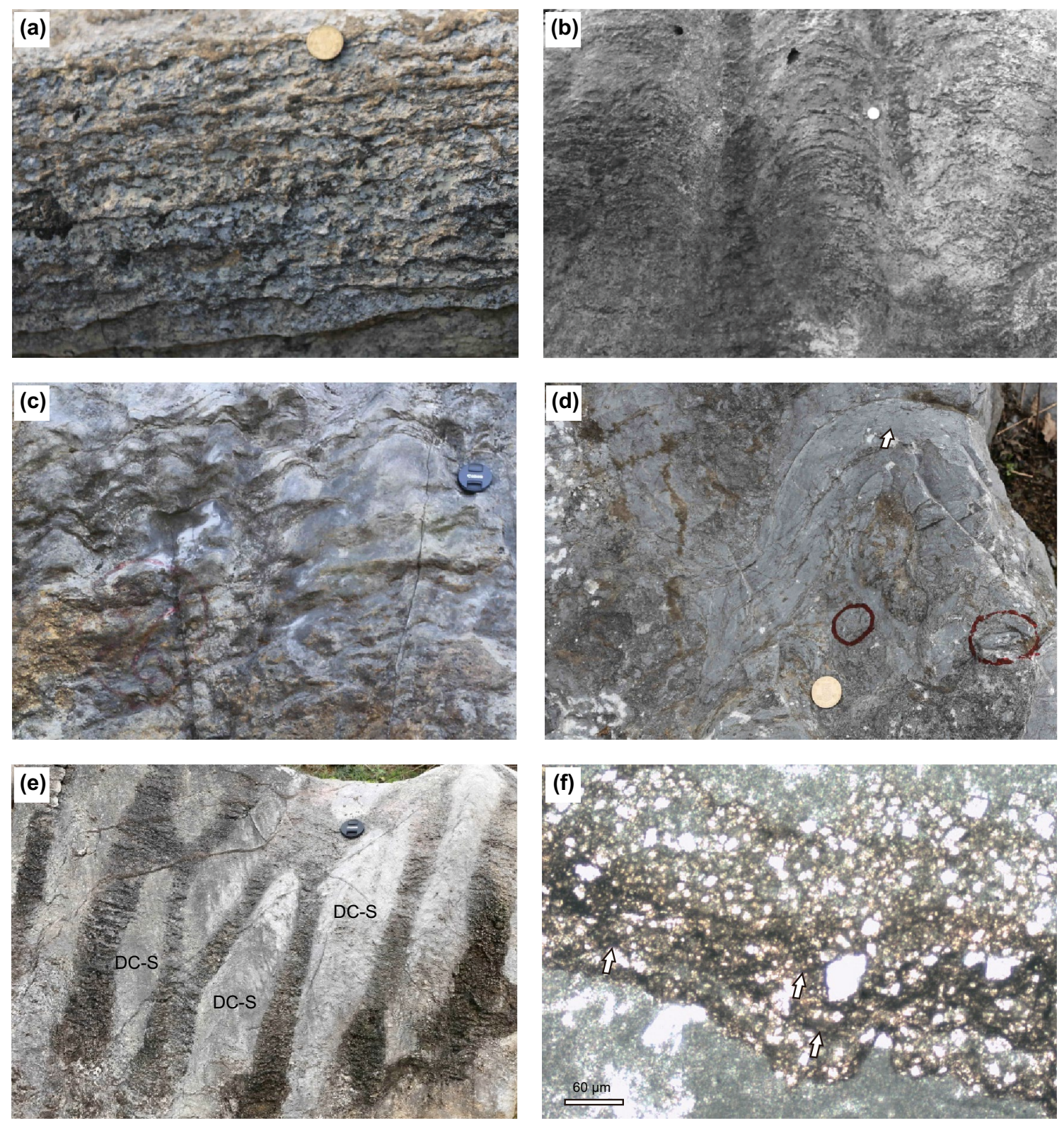

Fig. 3 Characteristics of Lower Ordovician microbialites in the Songzi Area. a Lamellar stromatolites from the Nanjinguan Formation; b wavy stromatolites from the Nanjinguan Formation; c wavy stromatolites from the Fenxiang Formation; d domal stromatolites, white arrows are dome-shaped uplifts, in the red circle are Calathium, seen in the Fenxiang Formation; e columnar stromatolites, and the DC-S represents dipyramidal stromatolite, seen in the Nanjinguan Formation; $\mathbf{f}$ the microscopic characteristics of the laminated stromatolites, the arrows show filamentous and intertwined Girvanella, developed in the Nanjinguan Formation

deposits. These deposits also represent a characteristic deposit of the wavy stromatolite reef, the interreef channel microfacies. The bioclasts are dominated by crinoid stems, and clots consisting of micritic clusters are also present. In the dark layers of this type of stromatolite, a large number of filamentous Girvanella microorganisms are observed oblique or perpendicular to the laminae. The Girvanella are mostly surrounded by micritic calcite, and some have recrystallized (Fig. 4a). This type of stromatolite developed on top of intrasparrudite, and in the
Fenxiang Formation, these stromatolites developed on top of biomicrosparite.

\section{(3) Columnar stromatolites}

Columnar stromatolites refer to stromatolites that have a cylindrical appearance, and these are relatively well developed in the study area. These stromatolites are mainly found in the Nanjinguan and Fenxiang Formations (Fig. 3e). Stromatolitic limestone appears thick to massive bedded and 

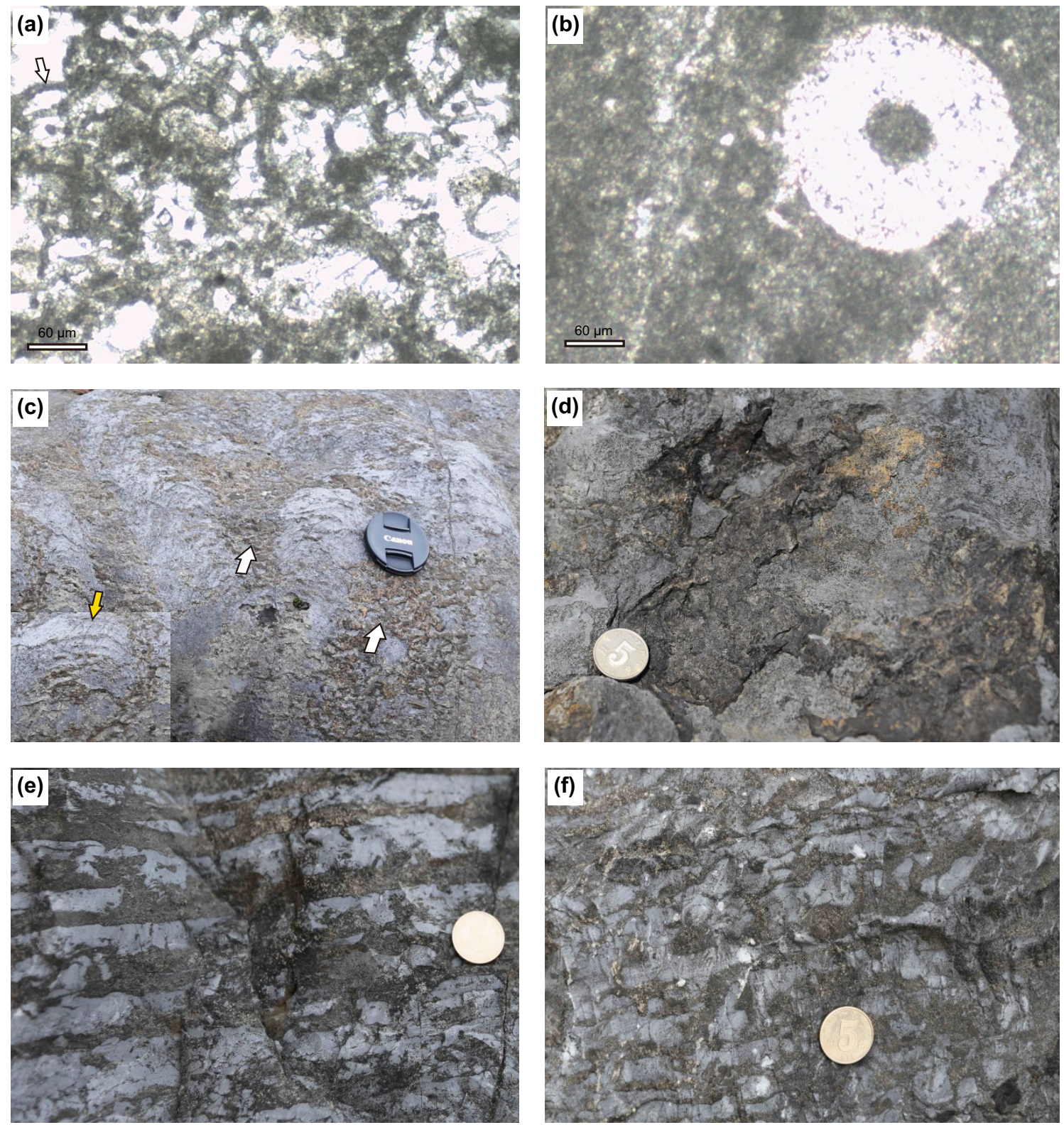

Fig. 4 Characteristics of Lower Ordovician microbialites in the Songzi Area. a Micrographic photograph of wavy stromatolite, arrowheads refer Girvanella tubular body, from the Honghuayuan Formation; b echinoderm clastics between layers of stromatolite, from the Nanjingguan Formation; $\mathbf{c}$ bioturbated thrombolites, the white arrows indicate the thrombolites, and the yellow arrows indicate the magnified features of the light and dark lamina between the thrombolites, from the Nanjingguan Formation; d speckled thrombolites, from the Nanjingguan Formation; e banded thrombolites, from the Nanjingguan Formation; f speckled thrombolites, from the Nanjingguan Formation. The camera lens cap is $12 \mathrm{~cm}$ in diameter, and the coin is $20 \mathrm{~mm}$ in diameter of $\mathbf{c}, \mathbf{d}, \mathbf{e}, \mathbf{f}$

distributed horizontally between the wavy stromatolite and the stratiform stromatolite in the study area. Columnar stromatolites are composed mostly of columnar bodies, which are stacked vertically and are upwardly convex. Each columnar body is composed of alternating layers of dark-colored algal laminae and light-colored laminae. The laminae around the stromatolite columnar body tend to droop and form an outer wall. The columns of columnar stromatolites generally have a circular or elliptical cross section or an irregular oval cross section, with diameters ranging from 8 to $50 \mathrm{~cm}$ and heights ranging from approximately $40-180 \mathrm{~cm}$. The longitudinal sections of the cylindrical stromatolite possess different forms: some coarsen upward, some fine upward and others are coarsest in the middle, with finer tops and bottoms. According to the combined features of the cross-sectional and longitudinal sections, the columnar stromatolites of the Nanjinguan and Fenxiang Formations of the study area can be classified as columnar stromatolites (cylinder-shaped), 
pyramidal stromatolites (fining upward), inverted pyramidal stromatolites (coarsening upward) and dipyramidal stromatolites (coarsest in the middle, newly named). The first three types are found in the Cambrian Mantou Formation in western Henan (Chang et al. 2013), and the dipyramidal stromatolite was discovered for the first time in this area (Fig. 3e). Longitudinally, the grain sizes of the upper and lower portions are finer than those of the middle. The internal laminar features are similar to those of other columnar laminates, all of which are curved upward. However, due to the thickness and development of the light layers, the dark layers are very thin, so it is difficult to show the features of the laminae in the field photographs. The sediments filling the space between the pillars of the columnar stromatolites are bioclasts and sand. The bioclasts are mainly stem stalks of pelmatozoan echinoderms, accounting for approximately $40 \%$. Additionally, a small amount of arenaceous sediment is present. The combined thickness of the light and dark laminae is approximately $8 \mathrm{~mm}$. The light laminae are thicker than the dark laminae and are almost as thick as the combined thickness of both the light and dark laminae. The dark layer is not well developed and is approximately $0.1 \mathrm{~mm}$ thick; it is much thinner than the equivalent structures in the wavy and stratiform stromatolites. This phenomenon may be related to the weaker development of cyanobacteria because of strong hydrodynamic conditions. Notably, the in situ vertical growth of the pelmatozoan echinoderms is visible in the interior of some columnar stromatolites, which together with cyanobacteria formed a barrier reef (Xiao et al. 2016).

In terms of microfacies, columnar stromatolites also have an inhomogeneous internal structure. The main component between the laminae is micritic calcite, followed by a small amount of bioclasts and arenaceous sediment. The bioclasts are mainly echinoderm fragments (Fig. 4b), followed by brachiopod fragments; a small amount of clots is also present. The gaps between adjacent columns are filled large amounts of bioclasts and arenaceous sediment, which constitute an important microfacies within the columnar stromatolitesinterchannel microfacies deposits. These deposits are also characteristic of columnar stromatolite reefs and represent interreef channel microfacies. The infilling bioclasts are dominated by crinoid ossicles, and clots consisting of micritic clusters are also present. The dark-colored laminae of the stromatolites are weakly developed, with occasional Girvanella microflora. The laminae are surrounded by sparry calcite and micrite calcite. Most of these stromatolites are built on sparry bioclast limestone.

\section{(4) Domal stromatolites}

The domal stromatolites are hemispherical stromatolites whose laminae bend toward the top, not down. This type of stromatolite is not as common as other types in the study area; some are observed in the upper part of the Fenxiang Formation where they are mostly solitary or located between stratiform stromatolites (Fig. 3d). The continuity of the laminae is good, and the mound-shaped curved laminae tend to fuse at the edge of the stromatolite and not protrude toward the bottom. In the domal stromatolites in the Fenxiang Formation, the light-colored laminae are better developed than the dark-colored laminae. The domal stromatolites have widths of 5-16 cm and heights of $10-30 \mathrm{~cm}$. In terms of microfacies, the domal stromatolites also possess an inhomogeneous internal structure. In the longitudinal direction, the structure can be divided into laminae and interlaminar zones. The interlaminar zones are mainly composed of micritic calcite, with few bioclasts and sand. In the lateral direction, the domal stromatolites can transition into calcarenite or stratiform stromatolitic limestone. This type of stromatolite is built on sandstone and bioclastic limestone.

\subsubsection{Thrombolites}

All thrombolites found in the study area were located in the Lower Ordovician strata. According to apparent characteristics and the large- and medium-scale structures of the thrombolites, this type of microbialite can be roughly divided into three types: speckled, reticulated and banded thrombolites (Figs. 4, 5). Furthermore, speckled thrombolites can be further divided into spotted (Fig. 4c, f) and patchy (Fig. 4d) types. Speckled thrombolites are found in the Nanjinguan Formation (Fig. 4c, d, f), and reticulated thrombolites are found in the Fenxiang Formation (Fig. 5a). Spotted and reticulated thrombolites are bioturbated thrombolites. These kinds of thrombolites were found in Ordovician strata for the first time, and their discovery is of great significance for the study of the genesis of Phanerozoic thrombolites.

\section{(1) Speckled thrombolites}

Speckled thrombolites were found in the lower part of the Lower Ordovician Nanjinguan Formation in the Liujiachang area. The basal surface is gray-brown, and the fresh surface is dark gray to grayish black. The large-scale structure of the thrombolite is thick to massive and approximately $55-115 \mathrm{~cm}$ thick. The medium-scale structure of the thrombolite in profile is spotted (Fig. 4c, f) and patchily (Fig. 4d), discontinuously or continuously distributed. The thrombolites have dimensions of $2 \times 3 \mathrm{~cm}$ to $8 \times 25 \mathrm{~cm}$ and account for approximately $20 \%-45 \%$ of the rock. The speckled thrombolite in plan view is roughly similar to that in profile and is also patchy, spotted or partially irregularly finely meshed. Interestingly, there are intermittent laminar textures within the spotted thrombolite in profile (Fig. 4c). The thickness of the laminae is not consistent, and the lightcolored laminae differ from the dark-colored laminae. A 

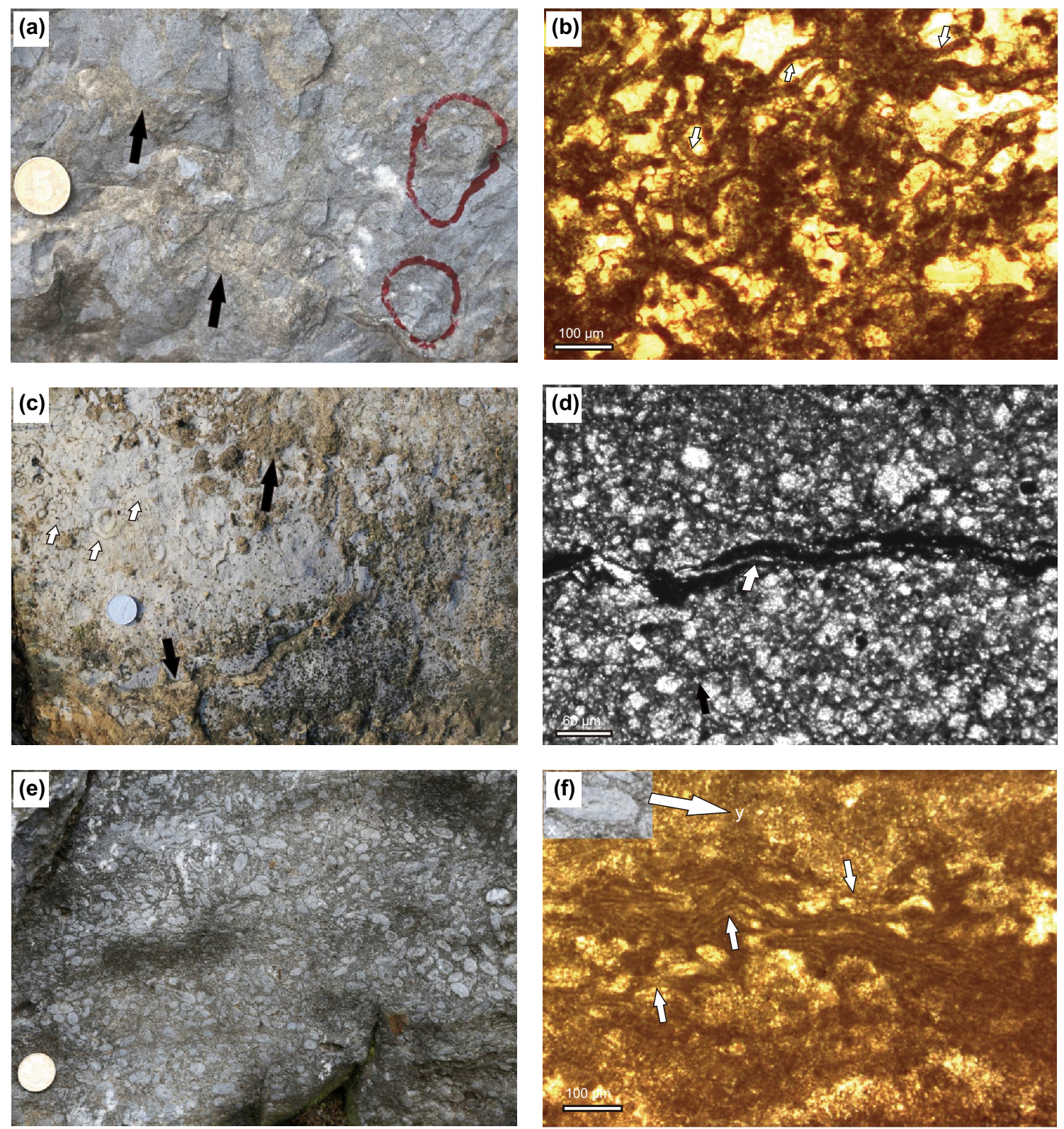

Fig. 5 Characteristics of microbialites of the Lower Ordovician in the Songzi Area. a Reticulated thrombolite, black arrowheads are thrombolites, and Ecculiomphalus fossils are in the red circle, from the Fenxiang Formation; b bioturbated thrombolite micrograph, white arrow indicating Girvanella, from the Nanjinguan Formation; c bioturbated thrombolite, white arrows are Ecculiomphalus, and black arrows are thrombolites, from the Nanjinguan Formation; $\mathbf{d}$ micrograph of banded thrombolite, white arrow refers filamentous microorganisms Girvanella, from Nanjinguan Formation; e Oncolite, from Fenxiang Formation; f micrograph of oncolite, $x$-Oncolite, $y$-magnification of $x$, small arrow indicating filamentous and twining Girvanella. The coin is $20 \mathrm{~mm}$ in diameter of Fig. 5

small amount of sand and bioclasts are present between the laminae.

In terms of microfacies, the speckled thrombolites possess an inhomogeneous internal structure. The dark-colored layers are mainly micritic clots, which are mostly composed of microcrystalline-crystalline calcite, followed by bioclasts and sand grains. The material between the laminae is mainly micritic calcite, followed by bioclasts and arenaceous sediment. Filamentous microorganisms, i.e., Girvanella, are intertwined with each other within thrombolites (Fig. 5b). These microorganisms are mostly surrounded by micritic calcite, with local sparry calcite. The speckled thrombolite is mostly built on sparry calcarenite.

It is worth pointing out that fossils of grazing Ecculiomphalus gastropods can be seen on the surface of the thrombolites and within them (Fig. 5c). Therefore, the formation of the thrombolites is considered to be associated with bioturbation (see discussion below). 


\section{(2) Reticulated thrombolite}

Reticulated thrombolites were found in the lower part of the Lower Ordovician Fenxiang Formation in the Liujiachang area. The basal surface was gray-brown, and the fresh surface was dark gray. The large-scale structure of the thrombolites is thickly bedded and has a thickness of approximately $52-76 \mathrm{~cm}$. In plan view, the medium-scale structure of the thrombolite is shaped like an irregular grid or irregular distribution (Fig. 5a). The size of the grid varies from $1.5 \times 1.5 \mathrm{~cm}$ to $5 \times 12 \mathrm{~cm}$. In profile, this type of thrombolite is an incompletely closed mesh, and the dark laminae have widths of $0.2-0.5 \mathrm{~mm}$. In terms of microfacies, the dark layers of the thrombolites mostly show different sizes of micritic clots, most of which are composed of microcrystalline-crystalline calcite, with local recrystallization.

Unlike speckled thrombolite, no laminae structure was found in the strata associated with reticulated thrombolites, but many fossils of grazing Ecculiomphalus gastropods were found on the surface of and within these thrombolites (Fig. 5a); Ecculiomphalus fossils are in the red circle. The authors of this paper believe that this type of thrombolite was formed by bioturbation.

\section{(3) Banded thrombolite}

Banded thrombolites are found in the lower part of the Lower Ordovician Nanjinguan Formation in the Liujiachang area. The basal surface is light gray, and the fresh surface is dark gray and grayish black. The large-scale structure of these thrombolites is thick bedded to massive, ranging from approximately $52-150 \mathrm{~cm}$ in thickness. In profile, the medium-scale structure of the thrombolites exhibits an approximately parallel banded distribution (Fig. 4e). The width of the bands is approximately $0.4-18 \mathrm{~cm}$, and the thrombolites account for approximately $35 \%-40 \%$ of the rock. There are no laminar structures in the interiors of these thrombolites in profile.

In terms of microfacies, the dark layers of the thrombolite are mostly expressed as clots and are characterized by micritic clusters, in which microcrystalline-crystalline calcite and small amounts of sand grains are occasionally observed. Notably, interwoven filamentous microorganisms, i.e., Girvanella, are present in the dark layer (Fig. 5d). These observations suggest that the formation of these thrombolites has a certain relationship with the activities of microorganisms.

\subsection{Granular types of microbialites}

The granular type of microbialites mainly includes coatedgrain oncolites and a few types of oolites, but this type of microbialite is dominated by the development of oncolites in the research area. This kind of microbialites is characterized by carbonate precipitation caused by the capture and binding of carbonate mud around rolling cores or particles by microorganism communities in middle- to high-energy seawater environments.

The oncolites in the study area were mainly found in the Fenxiang Formation (Fig. 5e, f). They were mostly medium to thick bedded, with a single-layer thickness of $50-80 \mathrm{~cm}$. Oncolitic limestone is mostly interbedded in the strata or interbedded with sparry arenaceous sediment and bioclastic limestone. The oncolites account for approximately $20 \%-45 \%$ of the rock and have diameters of $0.2-1.5 \mathrm{~cm}$ (with an average of approximately $1 \mathrm{~cm}$ ). Sparry cementation shows visible concentric circle structures inside the oncolites, mostly forming 3-9 layers. Furthermore, more Girvanella development, e.g., Oscillatoriopsis, is more visible in the dark layers than in the light layers (Fig. 5f). All these phenomena also illustrate that oncolites are a special type of microbialite.

\section{Analysis of the sedimentary environment of the microbialites}

According to the geometric characteristics, lithologies and sedimentary characteristics of the microbialites in the study area, this study analyzes the sedimentary environments of the various microbialites as follows and summarizes the depositional environment model (Fig. 6).

\subsection{Sedimentary environment of stromatolites}

The main feature of stratiform stromatolites is that their laminae are almost horizontal or exhibit only slight waviness, and their developmental lithology is mainly micrite. Only a small amount of fine clastics is present between the dark laminae. The base of the stratified stromatolites is calcarenite or dolomitic limestone, and it can be inferred that the hydrodynamic energy was relatively low; thus, these stromatolites may have formed in the intertidal zone in a fairly shallow environment. The wavy stromatolites are mostly distributed between the stratiform stromatolites and the columnar stromatolites in the transverse direction. Their laminae are wavy and have peaks and troughs. The underlying strata are mostly composed of calcarenite, and the main lithological component is micrite, with a small amount of dolomitic limestone. Small amounts of arenaceous sediment and bioclasts are also visible between the layers, and the color of these stromatolites varies from light gray to dark gray. These observations suggest that the formation of wavy stromatolites requires a certain amount of energy, and the water depth should be slightly greater than that of stratiform stromatolites. Therefore, the sedimentary environment is inferred to have been an intertidal 


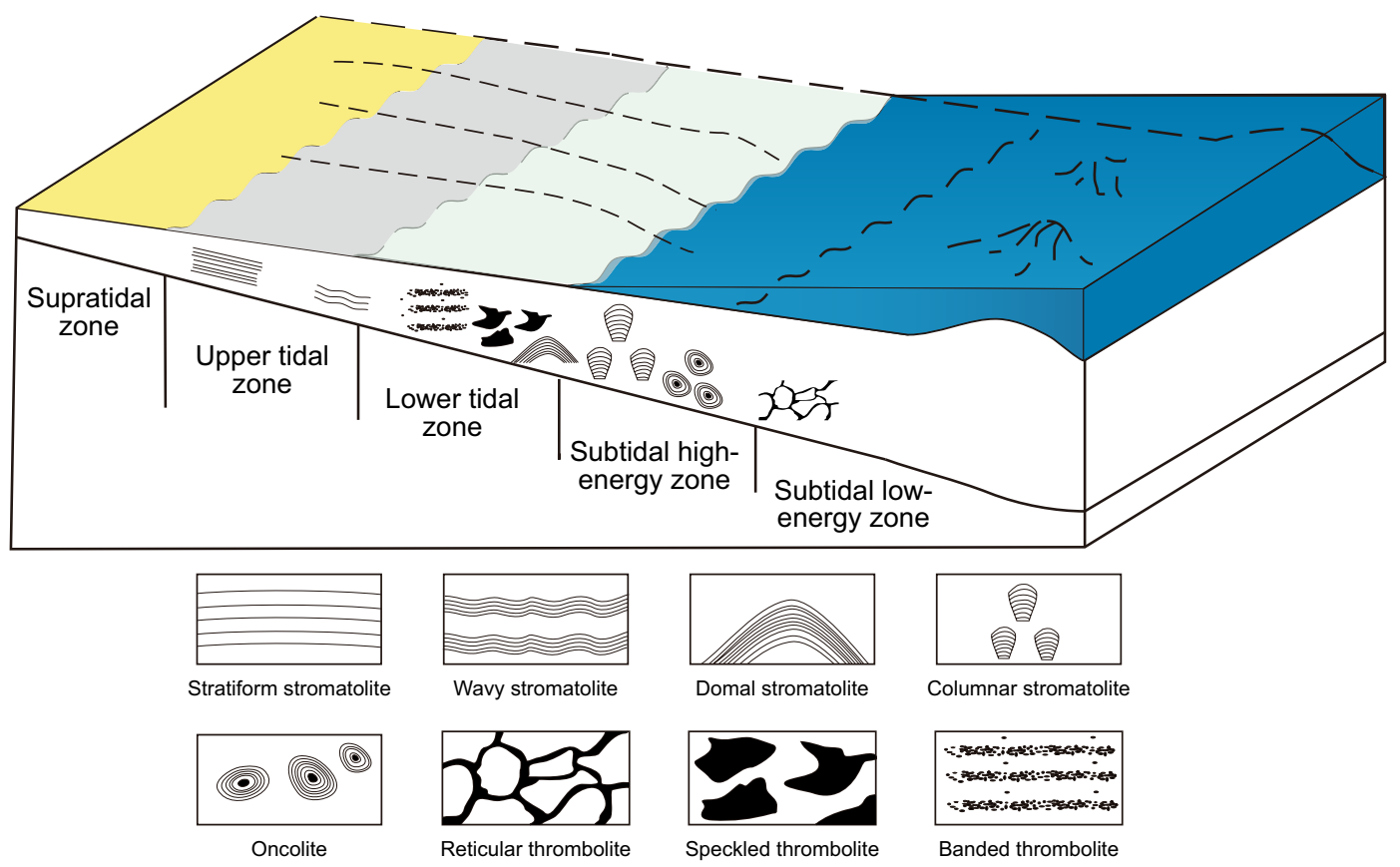

Fig. 6 Microbialite depositional patterns in the Lower Ordovician in the Songzi Area

zone environment, possibly in the lower part of the intertidal zone. The lateral distribution of domal stromatolites is relatively limited, and their formation mechanism and environment are similar to those of the wavy stromatolites.

The columnar stromatolites are distributed at the outer edge of the wavy stromatolites and are farther seaward than the other stromatolites. The material between the laminae is mainly micritic calcite, followed by small amounts of bioclasts and arenaceous sediment. The bioclasts are mainly echinoderm fragments (Fig. 4b), followed by brachiopod fragments; additionally, a few clots are observed. The gaps between adjacent columns are filled with numerous bioclasts and arenaceous sediments, which constitute important microfacies within the columnar stromatolite, i.e., interchannel microfacies deposits. This type of bioclastic deposit is mainly composed of stem stalks of stemmed echinoderms, which account for approximately $40 \%$, followed by a small amount of arenaceous sediment. The cement is mostly sparry calcite. These deposits represent interchannel deposits between the reefs of the columnar stromatolites. Most of these stromatolites are built on calcsparite bioclastic limestone. The above observations indicate that the formation of the columnar stromatolites required a higher-energy environment than that of the wavy stromatolites. Based on the above sedimentary characteristics, it is believed that the columnar stromatolites formed in the higher-energy environment from the lower part of the intertidal zone to the upper part of the subtidal zone.

\subsection{The depositional environment of clotted limestone}

The three types of thrombolites in the study area were all developed on sparry calcarenite or bioclastic limestone, indicating that they formed on shoals with a certain energy. The interior of the clotted limestone possesses a microcrystalline structure, and these limestones are mostly micritic calcite to microcrystalline calcite. The speckled clotted limestone and the stratiform limestone in the Nanjinguan Formation were partially replaced by fine-grained crystalline dolomite, although a small amount of fine-grained clastics and stem debris from echinoderms remain. In addition, Girvanella microflora can be seen in the dark layer of the boundary of the clotted limestone, and most of these organisms live in relatively restricted water. Therefore, the speckled clotted limestone likely formed in a limited intertidal zone with a certain amount of energy. The reticulated clotted limestone in the Fenxiang Formation is mainly composed of microcrystalline calcite, with no dolomite, and is overlain by a fine-grained gray shale, and floating graptolite fossils are present in the shale. The above observations reflect the deepening of the water body. The reticulated clotted limestone is thought to have likely formed in a low-energy environment below the tidal zone based on the internal microfacies and the sedimentary characteristics of the overlying and underlying strata. 


\subsection{The depositional environment of the oncolite}

The oncolites in the study area are found in the strata between the second section of the Nanjinguan Formation and the first section of the Fenxiang Formation. The oncolites are present as a single layer or interlayer or in alternating layers with spararenite and calcsparite bioclastic limestone. The oncolites are mostly ellipsoidal. The cores are mostly covered with bioclastic, calcarenite and calcirudite material, and the oncolites are commonly cemented with sparry calcite, indicating higher energy. Second, in most oncolites, wedge cross-bedding or parallel bedding is observed. In summary, the oncolites in the study area are thought to have formed in a high-energy environment in the intertidal zone or subtidal zone.

\section{Discussion}

\subsection{Analysis and discussion of the formation of thrombolites}

There is currently no unified understanding of the formation mechanism of clotted limestones. However, in terms of genesis, clotted limestone can be divided into two major types: protogenic and epigenetic. Moreover, it can be further divided into calcified microbial thrombolites, coarseaggregate agglomerates, bioturbated thrombolites, dendrites, travertine clots and postdepositional secondary clots (Riding 2000; Mei 2007b).

Among the clotted limestones found in this area, speckled clotted limestone and reticulated clotted limestone belong to the bioturbated type of clotted limestone. The evidence is as follows: First, grazing Ecculiomphalus fossils were found in both kinds of clotted limestone. The fossils were present sporadically or pervasively. In a $40 \times 40 \mathrm{~cm}$ area of the spotted thrombolites, the Ecculiomphalus fossils accounted for approximately $50 \%$ of the area (Fig. 5c). In some local areas where the organism is common, the distribution of thrombolites is very irregular because of grazing and disturbance. Therefore, inside areas with high contents of Ecculiomphalus, the thrombolites are very sporadic and feature only a very small number of small circular clots with a diameter of $0.2 \mathrm{~cm}$ (Fig. 5c). In the marginal area where the content of Ecculiomphalus gradually decreases, the thrombolites differ in shape due to gnawing and disturbance, and some are round, elliptical and $0.2-0.3 \mathrm{~cm}$ in diameter, whereas others feature long curved bands that are $0.2-0.3 \mathrm{~cm}$ in width, forming a fine irregular mesh (Figs. 4-3, 5-3). The existence of these patterns is the most direct evidence of bioturbation. Because Ecculiomphalus features a shell that resembles a flat spiral and moves slowly, they generally inhabited shallow marine areas and were extremely prolific in the Early
Ordovician. Most of them lived on carbonate rock mounds, and their abundant presence in microbialites indicates that they fed on submarine cyanobacteria (Garrett 1970). Additionally, the gastropod Ecculiomphalus is also found in the reticulated thrombolites, where it is present not only in the gaps in the grid (the lower circle of Fig. 5a) but also in the dark layers in the reticulated thrombolites (the upper circle of Fig. 5a). Due to the grazing and disturbance of Ecculiomphalus, the dark layers of the reticulated thrombolites show a different grid structure, with different thicknesses and an extremely irregular shape. Third, a fine laminar structure is present between the clots developed within the speckled clotted limestone. The characteristics of this laminar structure are similar to those of stromatolites, with the characteristic alternating light and dark laminae. Fourth, the authors found that in a large portion of the study area, the stratum of the speckled clotted limestone was horizontally connected to the strata of the wavy stromatolites. Although some scholars have suggested that the lateral relationship between stromatolites and thrombolites is complicated (Planavsky et al. 2009), a large number of grazing Ecculiomphalus gastropod fossils are found in the thrombolites, so the presence or absence of biological disturbance explains the genesis of the spotted thrombolites. In other words, the spotted thrombolites were formed by bioturbation of stromatolites.

The same situation is also observed in the Shijiachong Formation of the Neoproterozoic Shennongjia Group in Baokangmaqiao area, Hubei Province (Cao 1997; Cao and Yuan 2006). Cao (1997) discovered a variety of thrombolite limestones and morphologic-specific stromatolites that contain a marked "scar" produced by drilling and herbivorous animals. In addition, many stromatolites have been found to gradually transform into clotted limestone and form unusual distributions of stromatolite, clotted limestone and stromatolite-thrombolite combinations. Previous research provided valuable information for the understanding of the bioturbation-related formation mechanism of clotted limestone in the study area. The question of whether there are similar thrombolites in other times and regions requires further study.

It is worth pointing out that no laminar structure is found except for the discovery of a large number of grazing metazoan Ecculiomphalus in the reticulated thrombolites in the Fenxiang Formation. Therefore, is this kind of clotted limestone also formed by the bioturbation of stromatolites? The authors believe that further research and validation may be needed.

\subsection{The relationship between the development of microbialite and the great radiation of metazoans}

During the Early Ordovician period in the study area, there were three cycles of development of microbialites, namely 
the three depositional periods of the Nanjinguan, Fenxiang and Honghuayuan Formations. In terms of development characteristics, the number of layers and thicknesses of the microbialites gradually decreases from the bottom up, and the scale gradually decreases. The number, frequency and scale of the development of microbialites were largest during the deposition of the Nanjinguan Formation. There are three types of microbialites: stromatolites, thrombolites and oncolites. In this formation, there are two layers of stromatolite, four layers of oncolitic limestone and five layers of clotted limestone. In the upper part of the formation, the microbialites are smaller in scale, number and single-layer thickness. During the depositional period of the Fenxiang Formation, the frequency, number and scale of the three types of microbialite, namely stromatolite, clotted limestone and oncolite, gradually decreased. The Fenxiang Formation contains one layer of stromatolite and two layers of clotted limestone, and the thickness, scale and number of aggregates in the clotted limestone are smaller than those of the Nanjinguan Formation. The scale, frequency and quantity of microbialites in the Honghuayuan Formation are also significantly reduced, and the content decreases and eventually disappears. Therefore, what do the evolutionary characteristics of the Lower Ordovician microbialites in the study area illustrate? What caused the disappearance of microbialites at the end of the Florian period, and what is the relationship between them and the evolution of macroscopic organisms? These questions are issues about which many scholars think.

In terms of biological diversity, there are three peak periods of biological evolution in the Ordovician (Sepkoski et al. 1981; Sepkoski 1995). However, the most important peak period is the first peak in the Early or Middle Ordovician period. During the Early and Middle Ordovician, marine invertebrates showed large differences and considerable radiation. Sepkoski analyzed the evolution of the diversity of different species in the early Paleozoic from the perspective of global biological evolution data (Sepkoski et al. 1981; Sepkoski 1995). The analysis results show that the diversity of different types of species significantly increased during the Ordovician period, but the starting times of their radiation were not synchronous. For example, trilobites, brachiopods, graptolites, most mollusks and echinoderms began to show significant increases in diversity at the beginning of the Ordovician period. The diversity of other biological groups exhibited dissimilar evolutionary progress; for example, the diversity of coral almost exponentially accelerated, while that of some mollusks and brachiopods increased in steps (Zhang et al. 2009). Therefore, some scholars believe that the gradual decline of thrombolites and stromatolite over the history of the earth has a certain relationship with the increase in the abundance of metazoans. In other words, the reduction in the abundance of clotted limestone and stromatolites is related to the continuous feeding of metazoans on the algae that formed stromatolites and clotted limestone. Reid and Visscher (2000) found numerous traces of internal laminae destroyed by creatures such as clams and sponges in modern stromatolites, and obvious biological traces are preserved in laminae (Reid and Visscher 2000). Chinese scholars, such as Cao and others, have found scars left by the destruction of drilling animals and herbivores in the stromatolites in the Shijiachong Formation of the Shennongjia Group in Baokangmaqiao, Hubei Province (Cao 1997; Cao and Yuan 2006). These scars formed an unusual collection of stromatolites, clotted limestone and stromatolite-thrombolite combinations. These examples are evidence of the increase in the abundance of metazoans and the consequent grazing pressure on stromatolites. Some scholars have suggested that the development and decline of microbialites may have a certain relationship with changes in the chemical properties of the seawater (Riding and Liang 2005). However, the changes in the chemical properties of the Ordovician seawater were not as different as they were after the Ordovician (Yang 2018). Therefore, this situation also needs further research and verification.

From the development and evolution of microbialites in this area, this article agrees with the above view that the main reason for the gradual decline in microbialites over time is the result of the increase in the number of metazoans and their continuous feeding on the algal microbes that formed the microbialites. First, this point can be confirmed from the diversity characteristics of biological evolution; that is, the increase in benthonic metazoans from the Early Ordovician to the initial stage of the Middle Ordovician has a corresponding relationship with the reduction of microbialites. Second, we found benthic grazing Ecculiomphalus mollusk fossils in the majority of stromatolites and clotted limestone in the study area (Fig. 5a, c), and this type of organism is especially clustered in local intervals (Fig. 5c). These organisms fed on the microbial algae that formed the microbialites, causing a continuous decrease in the number of microbialites over time. Moreover, this feeding behavior also caused the microbialites to transition from stromatolites into bioturbated-type thrombolites with or without laminae. Thus, metazoans are the main reason for the formation of bioturbated thrombolites.

\section{Hydrocarbon potential analysis}

Research shows that the bacterial and algal microbes in modern marine stromatolites reproduce rapidly, so they have high biological productivity (Walter 1994). Therefore, some scholars believe that under certain conditions, microbialites are beneficial to the preservation of organic matter, and they have a certain hydrocarbon generation potential (Gerdes and 
Krumbein 1987; Yang et al. 2007) and can be treated as carbonate source rocks.

The main types of microbial carbonate in the study area are stromatolites, thrombolites and oncolites, among which stromatolites are dominant. Based on the thick layer of microbialites, we collected source rock samples from an outcrop and carried out hydrocarbon potential tests in the geochemistry laboratory of Yangtze University, which has the national metrological certification. The results of the analysis are shown in Table 1.

The abundance of organic matter is the most basic index for evaluating source rocks. The evaluation criteria for shale source rocks are consistent both in China and internationally, but the criteria for carbonate source rocks differ due to their low organic carbon content (the peak value of organic carbon samples around the world ranges from $0.12 \%$ to 0.25\%) (Gehman 1962). Scholars in China and elsewhere have also proposed a lower limit of organic carbon abundance and different evaluation criteria for different carbonate rocks (Gehman 1962; Chen et al. 2014). The organic carbon abundance of the microbialites in this area has a tendency to gradually decrease with time, but the average content of organic carbon is up to $0.19 \%$, indicating that the microbialites in this area have a good hydrocarbon generation potential. However, in terms of the stratigraphic development, the organic matter abundance of the microbialites in the Nanjinguan Formation is higher than that of the Fenxiang and Honghuayuan Formations, and the content of the organic carbon in the stromatolites and thrombolites in the Nanjinguan Formation is $0.15 \%-0.21 \%$. Consequently, the stromatolites and thrombolites in the Nanjinguan Formation represent better source rocks than those in the other formations. The organic carbon contents of the microbialites in the Fenxiang and Honghuayuan Formations are less than $0.15 \%$ and represent lower-quality source rocks. This phenomenon may be related to the relatively restricted environment of the Nanjinguan Formation in contrast to the relatively open environments of the Fenxiang and Honghuayuan Formations.

Table 1 Organic carbon content of Lower Ordovician microbial carbonate in Liujiachang area

\begin{tabular}{llll}
\hline Formation & Sample number & Microbialite types & $\begin{array}{l}\text { Organic } \\
\text { carbon, \% }\end{array}$ \\
\hline $\begin{array}{l}\text { Honghuayuan } \\
\text { Formation }\end{array}$ & LO1h-34 & Stromatolite & 0.08 \\
$\begin{array}{l}\text { Fenxiang Forma- } \\
\text { tion }\end{array}$ & LO1f-31 & Stromatolite & 0.1 \\
& LO1f-22 & Oncolite & 0.12 \\
Nanjinguan Forma- & LO1n-14 & Thrombolite & 0.15 \\
tion & LO1n-8 & Shrombolite & 0.21 \\
\hline
\end{tabular}

\section{Conclusions}

Through the study of the Lower Ordovician microbialites in the Liujiachang area of Songzi, this paper has obtained the following understanding:

(1) Microbialites were found in the Lower Ordovician Nanjinguan, Fenxiang and Honghuayuan Formations in the study area. Based on the growth forms of the microbialites, the microbialites are divided into two major types, namely nongranular and granular microbialites, in this paper. The nongranular microbialites mainly include stromatolites, thrombolites, dendrolites, leiolites and laminites. The granular microbialites are mainly oncolites but may include a small amount of microbiogenic oolite. In the vertical direction, the microbialites decrease in size, thickness and number.

(2) According to the geometric features, the stromatolites in the study area were divided into stratiform, wavy, columnar and domal stromatolites based on shape. The dipyramidal stromatolite represents a newly discovered and named type. Based on the shapes of the clotted limestone, three types of thrombolites are recognized: speckled, reticulated and banded. Fossils of grazing Ecculiomphalus mollusks and traces of bioturbation are observed in the speckled and reticulated thrombolites. This paper considers that these two kinds of thrombolite represent bioturbated thrombolites. This discovery not only fills gaps in the field of domestic Ordovician bioturbated thrombolites but also provides new information for the study of thrombolites in general.

(3) Based on the analysis of the sedimentary characteristics, the sedimentary environment of various types of microbialites is explained. This article concludes that the stratiform stromatolites, wavy stromatolites, speckled clotted limestone and banded limestone formed in the intertidal zone. The domal stromatolites and columnar stromatolites formed between the lower intertidal zone and the upper subtidal zone. The reticulated thrombolites formed in the low-energy environment of the subtidal zone. The paper summarizes the distributional patterns of the depositional environments.

(4) This article discusses the relationship between the development of microbial carbonate and the radiation of metazoans in the Early to Middle Ordovician. According to the correspondence between stepwise and rapid radiation of metazoans and the abrupt reduction in microbialites from the late Early Ordovician to the early Middle Ordovician, combined with the discovery of the fossils of grazing Ecculiomphalus in stromatolites and clotted limestone in the study area, the authors suggest that the abundance of microbialites gradually 
decreased over time in response to the rapid increase in the abundance of metazoans. Notably, the grazers not only grazed on the bacteria that formed the stromatolite but also caused a continuous decrease in the number of stromatolites and disrupted the growth state of the stromatolites. As a result, unique bioturbated thrombolites formed in the study area.

(5) Hydrocarbon potential analysis shows that the organic matter abundance of the microbialites in the Nanjinguan Formation is higher than that in the Fenxiang and Honghuayuan Formations and that the content of the organic carbon in the stromatolites and thrombolites in the Nanjinguan Formation is $0.15 \%-0.21 \%$. As a result, the stromatolites and thrombolites in the Nanjinguan Formation represent better source rocks than those in the other formations.

Acknowledgements This research Project was supported by the National Natural Science Fund of China (Grant No. 41572322) and Hubei Innovation Group Fund (Grant No. 2015CFA024). We thank two anonymous reviewers for their constructive reviews that greatly improved the manuscript.

Open Access This article is distributed under the terms of the Creative Commons Attribution 4.0 International License (http://creativeco mmons.org/licenses/by/4.0/), which permits unrestricted use, distribution, and reproduction in any medium, provided you give appropriate credit to the original author(s) and the source, provide a link to the Creative Commons license, and indicate if changes were made.

\section{References}

Adachi N, Ezaki Y, Liu J. Early Ordovician shift in reef construction from microbial to metazoan reefs. Palaios. 2011;26(1-2):106-14. https://doi.org/10.2110/palo.2010.p10-097r.

Aitken JD. Classification and environmental significance of cryptalgal limestone and dolomites, with illustration from the Cambrian and Ordovician of Southwestern Alberta. Sediment Petrol. 1967;37(4):1163-78. https://doi.org/10.1306/74D7185C-2B2111D7-8648000102C1865D.

Burne RV, Moore LS. Microbialites: organosedimentary deposits of benthic microbial communities. Palaios. 1987;2(3):241-54. https ://doi.org/10.2307/3514674.

Cao R. Evidence for possible metazoan activity in Neoproterozoic aberrant stromatolites and thrombolite structures. Acta Palaeontol Sin. 1997;38(3):294-302. https://doi.org/10.3969/j.issn.00016616.1999.03.002 (in Chinese).

Cao R, Yuan X. Stromatolite. Hefei: China University of Science and Technology Press; 2006. p. 15-235 (in Chinese).

Cao J, Liu J, Ezaki Y, Adachi N. Lower Ordovician reefs in the Honghuayuan Formation at Dongzhi, Anhui: microbial reefs just prior to the Ordovician biodiversification. Acta Sci Nat Univ Pekin. 2009;45(2):279-88. https://doi.org/10.13209/j.04798023.2009.043 (in Chinese).

Chang Y, Qi Y, Zheng W, et al. Sedimentary characteristics and paleoenvironmental significance of the stromatolite in the Cambrian Mantou Formation in the west of Henan Province. Acta
Sedimentol Sin. 2013;31(1):10-9. https://doi.org/10.14027/j.cnki. cjxb.2013.01.011 (in Chinese).

Chen Y, Yang Z, Wang S, et al. Discussion on the lower limit of organic abundance of effective hydrocarbon expulsion for the source rock from the Majiagou Formation in the Ordos Basin: taking the well Longtan 1 as an example. Nat Gas Geosci. 2014;25(11):171826. https://doi.org/10.11764/j.issn.1672-1926.2014.11.1718 (in Chinese).

Cloud PE, Semikhatov ME. Proterozoic stromatolite zonation. Am J Sci. 1969;267:1017-61. https://doi.org/10.2475/ajs.267.9.1017.

Feldmann M, McKenzie JA. Messinian stromatolite-thrombolite associations, Santa Pola, SE Spain: an analogue for the palaeozoic. Sedimentology. 1997;44(5):893-914. https://doi. org/10.1046/j.1365-3091.1997.d01-53.x.

Garrett P. Phanerozoic stromatolites: noncompetitive ecologic restriction by grazing and burrowing animals. Science. 1970;169(3941):171-3. https://doi.org/10.1126/scien ce.169.3941.171.

Gehman HM. Organic matter in limestones. Geochim Cosmochim Acta. 1962;26(8):885-97. https://doi.org/10.1016/00167037(62)90118-7.

Gerdes G, Krumbein WE. Biolaminated deposits. Lecture notes in earth sciences. New York: Springer; 1987. p. 1-183.

Golubic $\mathrm{S}$. The relationship between blue-green algae and carbonate deposits. In: Carr NG, Whitton BA, editors. The biology of bluegreen algae, chapter 21. Oxford: Blackwell Scientific Publications; 1973. p. 434-72.

Golubic S. Organisms that build stromatolites. In: Water MR, editor. Stromatolites development in sedimentology, vol. 20. Amsterdam: Elsevier; 1976. p. 113-26.

Hicks M, Rowland SM. Early Cambrian microbial reefs, archaeocyathan inter-reef communities and associated facies of the Yangtze Platform. Palaeogeogr Palaeoclimatol Palaeoecol. 2009;281(12):137-53. https://doi.org/10.1016/j.palaeo.2009.07.018.

Hofmann HJ, Jackson GD. Proterozoic ministromatolites with radialfibrous fabric. Sedimentology. 1987;34(6):963-71.

Li G, Wu Q. The early Ordovician (Nanjinguan period) bioherms of northwestern Hunan and its forming environment. J Stratigr. 2001;25(1):48-50. https://doi.org/10.3969/j.issn.02534959.2001.01.010 (in Chinese).

Knoll AH, Semikhatov MA. The genesis and time distribution of two distinctive Proterozoic stromatolite microstructures. Palaios. 1998;13(5):408-22. https://doi.org/10.2307/3515471.

Kruse PD, Zhuravlev AY. Middle-late Cambrian Rankenella-Girvanella reefs of the Mila Formation, northern Iran. Can J Earth Sci. 2008;45(6):619-39. https://doi.org/10.1139/E08-016.

Mei M. Revised classification of microbial carbonates: complementing the classification of limestones. Earth Sci Front. 2007a;14(5):22234. https://doi.org/10.1016/S1872-5791(07)60044-X.

Mei M. Discussion on advances of microbial carbonates from the terminological change of thrombolites. Geol Sci Technol Inf. 2007b;26(6):1-9. https://doi.org/10.3969/j. issn.1000-7849.2007.06.001.

Mei M, Lu L. The baffling buildup reef of Honghuayuanian age, Ordovician in Zhangzhai, Yuping County, Guizhou. Acta Sedimentol Sin. 1991;9(3):80-7. https://doi.org/10.14027/j.cnki. cjxb.1991.03.010 (in Chinese).

Myrow PM. Depositional history of pre-Devonian strata and timing of Ross orogenic tectonism in the central Transantarctic Mountains, Antarctica. GSA Bull. 2002;114(9):1070-88. https ://doi.org/10.1130/0016-7606(2002)114\%3c1070:DHOPD $\mathrm{S} \% 3 \mathrm{e} 2.0 . \mathrm{CO} ; 2$

Planavsky N, Reid RP, Lyons TW, et al. Formation and diagenesis of modern marine calcified cyanobacteria. Geobiology. 2009;7(5):566-76. https://doi.org/10.111 $1 / \mathrm{j} .1472-4669.2009 .00216 . x$. 
Reid RP, Visscher PT. The role of microbes in accretion, lamination and early lithification of modern marine stromatolites. Nature. 2000;406(6799):989-92. https://doi.org/10.1038/35023158.

Riding R. Calcified cyanobacteria. In: Riding R, editor. Calcareous algae and stromatolites. Berlin: Springer; 1991. p. 55-87.

Riding R. Microbial carbonates: geological record of calcified bacterial-algal mats and biofilms. Sedimentology. 2000;47(s1):179214. https://doi.org/10.1046/j.1365-3091.2000.00003.x.

Riding R, Liang L. Geobiology of microbial carbonates: metazoan and seawater saturation state influences on secular trends during the phanerozoic. Palaeogeogr Palaeoclimatol Palaeoecol. 2005;219(1):101-15. https://doi.org/10.1016/j.palae o.2004.11.018

Rowland SM, Shapiro RS. Reef patterns in the Cambrian and earliest Ordovician. In: Flügel E, Kiessling W, Golonka J, editors. Phanerozoic reef patterns. Flagstaff: SEPM Special Publication; 2002. p. 239-69.

Sepkoski JJ Jr. The Ordovician radiations: diversification and extinction shown by global genus-level taxonomic data. In: Cooper JD, Droser ML, Finney SC, editors. Ordovician Odyssey: short papers for the 7th international symposium on the Ordovician system. California: SEPM; 1995. p. 393-6.

Sepkoski JJ Jr, Bambach RK, Raup DM, et al. Phanerozoic marine diversity and the fossil record. Nature. 1981;293(5832):435-7. https://doi.org/10.1038/293435a0.

Semikhatov MA, Raaben ME. Proterozoic stromatolite taxonomy and biostratigraphy. In: Riding RE, Awramik SM, editors. Microbial sediments. Berlin: Springer; 2000. p. 295-306.

Shapiro RS, Awramik SM. Favosamaceria Cooperi new group and form: a widely dispersed, time-restricted thrombolite. J Paleontol. 2006;80(3):411-22. https://doi.org/10.1666/00223360(2006)80\%5b411:FCNGAF\%5d2.0.

Walter MR. Stromatolites: the main geological source of information on the evolution of early benthos. In: Bengtson S, editor. Early life on earth. New York: Columbia U.P.; 1994. p. 270-86.

Wang J, Deng X, Wang G, et al. Types and biotic successions of Ordovician reefs in China. Chin Sci Bull. 2012;57(10):1160-8. https ://doi.org/10.1007/s11434-011-4936-7.

Xiao C, Yang W, Liu B, et al. Discovery of Batostoma genus in early and middle Ordovician and its geological function and ecology in the middle Yangtze area. Chin Sci Bull. 1993;38(14):1314-5. https://doi.org/10.1007/bf02677081 (in Chinese).

Xiao C, Liu L, Luo C, et al. Paleoecology of organic reef (Ordovician) in the Lunnan area, Tarim Basin. Xinjiang Pet Geol. 1995;16(1):38-42. https://doi.org/10.1007/bf02951625 (in Chinese).

Xiao C, Jiang Y, Zhu Z, et al. Discussion about the sequence stratigraphy of Ordovician and the sedimentary environment of Wufeng
Formation in Yangtze Area. Geol J China Univ. 1996;3:33946. https://doi.org/10.16108/j.issn1006-7493.1996.03.009 (in Chinese).

Xiao C, Cui J, Zhu Z, et al. A study on palaeoecology of the lower Ordovician reefs in the Yichang area, Hubei. Geol Rev. 2004;50(5):520-9. https://doi.org/10.3321/j.issn:03715736.2004.05.011 (in Chinese).

Xiao C, Li M, Yang W, et al. Palaeoecology of early Ordovician reefs in the Yichang Area, Hubei-a correlation of organic reefs between early Ordovician and Jurassic. Acta Geol Sin. 2011;85(5):100315. https://doi.org/10.1111/j.1755-6724.2011.00235.x.

Xiao C, Tian Y, Xiao S, et al. Discovery of early Pelmatozoan reefs in the Tremadocian in Liujiachang, Songzi. Earth Sci Front. 2016;23(3):170-7. https://doi.org/10.13745/j.esf.2016.03.021 (in Chinese).

Xu L, Xiao C, Gong W, et al. Discussion about the origin of deep sea in the Guanyinqiao member of Wufeng Formation in the Upper Ordovician in Yangtze Area. Acta Geol Sin. 2004;78(6):72632. https://doi.org/10.3321/j.issn:0001-5717.2004.06.002 (in Chinese).

Yang Z. Research on sedimentary characteristics of stromatolites from Lower Ordovician, Songzi City, Hubei Province. Master's thesis of Yangtze University; 2018. p. 41-59 (in Chinese).

Yang H, Wang Y, Chen L, et al. Calci-microbialite as a potential source rock and its geomicrobiological processes. Front. Earth Sci. China. 2007;1(4):438-43. https://doi.org/10.1007/s 1170 7-007-0054-X.

Zhang Y, Hofmann HJ. Precambrian Stromatolites: image analysis of lamina shape. J Geol. 1982;90(3):235-68. https://doi. org/10.1086/628678.

Zhang Y, Zhan R, Fan J. Key scientific issues in the study of Ordovician biomass radiation, vol. 39(2). Beijing: Science in China Press; 2009. p. 129-43. https://doi.org/10.1016/s1874-8651(10)60080 -4 (in Chinese).

Zhuravlev AY, Wood RA. Anoxia as the cause of the mid-Early Cambrian (Botomian) extinction event. Geology. 1996;24(4):311-4. https://doi.org/10.1130/0091-7613(1996)024\%3c0311:AATCO $\mathrm{T} \% 3 \mathrm{e} 2.3 . \mathrm{CO} ; 2$.

Zhu S. Stromatolites. Tianjin: Tianjin University Press; 1993. p. 39-50 (in Chinese).

Zhu Z, Liu B, Meng X. Early Ordovician organic reefs in Songzi, Hubei. Oil Gas Geol. 1990;11(4):418-28. https://doi.org/10.11743 logg19900408 (in Chinese).

Zhu Z, Hu M, Xiao C, et al. Study on oil geology of upper SinianOrdovician in southwestern Hubei and northwestern Hunan. Beijing: Geological Publishing House; 1995. p. 8-143 (in Chinese).

Zhu Z, Hu M, Liu B, et al. Early-middle Ordovician reef of China. Beijing: Geological Publishing House; 2006. p. 120-78 (in Chinese). 